\title{
Editorial: As rodadas de correções e a carta-resposta do autor à aprovação condicionada - sobre o controle e o aprimoramento dos artigos no processo editorial científico
}

\author{
Editorial: The correction rounds and the author's response letter \\ to the article's conditional approval - the evaluation and the \\ improvement of papers in the scientific editorial process
}

Vinicius Gomes de Vasconcellos

\begin{abstract}
Doutorando em Direito na Universidade de São Paulo - São Paulo/SP
Editor-chefe da RBDPP e editor-assistente da RBCCRIM

vgomesv@gmail.com

lattes.cnpq.br/9628659956663949

orcid.org/0000-0003-2020-5516

P publons.com/a/1174099/
\end{abstract}

Resumo: Este editorial pretende examinar a sistemática da etapa de rodadas de correções nos casos de artigos que recebem a decisão de "aprovação condicionada a revisões", a partir dos pareceres dos avaliadores e da equipe editorial da revista. Com fundamento no reforço da importância de tal etapa para a produção de conhecimento científico consistente, serão apresentadas premissas e orientações à atuação do autor para correção do artigo e redação da carta-resposta à equipe editorial.

Palavras-chave: editorial; rodadas de correções; autor; controle por pares; pareceres.

AвSTRACT: This editorial intends to examine the systematics of the correction rounds in the cases of articles that receive the decision of "conditional approval", based on the reviewers' comments and the evaluation of the journal editorial team. Besides reinforcing the importance of such phase to the production of consistent scientific knowledge, premises and guidelines will be presented to inform the author's action to correct the article and write the response letter to the editorial board.

KEY-WORDS: editorial; correction rounds; author; peer review; reviewers' comments. 
Analisados os aspectos relevantes dos papéis de editores e avaliadores no processo editorial científico, ${ }^{1}$ deve-se expor algumas considerações sobre a atuação de outro ator fundamental da produção de conhecimento em periódicos: o autor. Assim, este editorial pretende examinar a sistemática da etapa de rodadas de correções, que ocorre nos casos de aprovações de artigos condicionadas a aprimoramentos a partir das críticas e sugestões de pareceristas e editores (também denominada de revise and resubmit).

Trata-se de situação extremamente corriqueira, pois são excepcionais (ou até inexistentes) os casos de aprovação incondicionada em revistas com um processo editorial sério. ${ }^{2}$ Para tanto, serão apresentadas premissas e orientações à atuação do autor diante de tais circunstâncias e à redação da carta-resposta ao editor.

A fase das rodadas de correções é um elemento de central importância ao processo editorial científico, ${ }^{3}$ pois é por meio dela (e da posterior análise sobre as alterações e respostas do autor) que se assegurará efetividade ao controle por pares. De nada adiantaria o empenho dos avaliadores para apontar críticas e sugestões se os autores pudessem simplesmente ignorar suas considerações. Conforme Pamela Silver, "os dois passos essenciais no processo de revisão são: 1) escrever pareceres úteis e construtivos aos artigos; e, 2) responder a tais críticas de um modo positivo e construtivo". ${ }^{*}$

Assim, encaminhados os pareceres aos autores, deverá ser enviada versão corrigida do artigo (com marcações das alterações) e uma carta (e-mail) de respostas às críticas e sugestões, onde se aponte o que foi atendido e se motive adequadamente o que eventualmente for recusado. A verificação de tal réplica dos autores é realizada pela equipe

1 VASCONCELLOS. Editorial: a função do periódico científico e do editor para a produção do conhecimento no Direito e nas ciências criminais, p. 9-17; VASCONCELLOS. Editorial: controle por pares e a função do revisor - premissas e orientações para uma avaliação consistente, p. 437-458.

2 Sobre as possíveis decisões editoriais e a raridade de uma aprovação plena: CUMMINGS; RIVARA. Responding to reviewer's comments on submitted articles, p. 105-106.

3 FERREIRA. Responder aos Revisores, p. 5.

4 SILVER. Advice for early-career peer reviewers and authors responding to peer reviews, p. 1074 (tradução livre). 
editorial do periódico. Excepcionalmente, por exemplo, em razão da complexidade da temática, pode-se solicitar nova avaliação do mesmo parecerista ou até de outro avaliador. Por isso, denomina-se fase de rodadas de correções no plural, pois pode (e isso é corriqueiro em revistas de excelência) haver mais de uma solicitação de correções aos autores, com a indicação de novas sugestões ou a reiteração de outras ignoradas ou não razoavelmente recusadas.

Portanto, mesmo após o controle por pares e a aprovação preliminar condicionada, um artigo pode (e deve) ser rejeitado, se os pareceres não forem considerados pelos autores, se problematizações não forem adequadamente respondidas ou se as justificativas à não aceitação de sugestões pertinentes forem inconsistentes. Para obter um resultado positivo diante de tal situação, aponta-se aqui um resumo das principais orientações:

\section{ORIENTAÇÕES AOS AUTORES}

1. Confirme o recebimento do e-mail ao editor e responda se o prazo apontado é viável;

2. Responda todas as críticas e sugestões, tanto da equipe editorial como dos avaliadores, demonstrando interesse em aprimorar o artigo;

3. Após o texto transcrito dos pareceres, responda embaixo de cada item/ crítica/sugestão com outra cor de letra;

4. Responda de modo direto e preciso, com motivação suficiente e consistente;

5. Mais importante do que contestar a crítica é aprimorar efetivamente o texto do artigo a partir do problema apontado;

6. Destaque as alterações realizadas no arquivo do artigo (utilize o arquivo enviado em anexo no e-mail da decisão editorial, pois ele já está formatado e marcará automaticamente as modificações).

Certamente, o empenho do pesquisador ao trabalho que resultará no artigo submetido se inicia em momento muito anterior à submissão ao processo editorial. Autores levam meses ou até anos planejando, executando e redigindo seus manuscritos, de modo que so- 
mente após um momento de desapego (ou pressão para publicação) é que se romperá pela primeira vez a relação direta com o trabalho e se enviará uma versão preliminarmente "finalizada" do manuscrito para avaliação por pares.

Contudo, esse primeiro rompimento deve necessariamente ser assim percebido: considerando que o processo editorial científico de revistas de qualidade resultará em críticas e sugestões, o autor precisa ter plena consciência de que retomará futuramente o contato com o trabalho para as rodadas de correções. Essa é uma premissa fundamental a ser assentada: o empenho do autor não se encerra com a submissão do artigo ao periódico, mas ainda haverá muito a ser feito até que se tenha efetivamente a versão final para publicação.

Raríssimos são os casos de aprovação direta de uma submissão para publicação sem qualquer alteração do artigo, já que, considerando-se a inexistência de perfeição e a pluralidade de perspectivas adotadas por cada pesquisador, quase sempre serão apontadas críticas e correções ao trabalho. ${ }^{5}$ Inclusive, pode-se até afirmar que um parecer sem qualquer sugestão tenderá a aparentar certa falta de empenho do avaliador, já que a consideração dedicada de teses inéditas sustentadas pelo autor deve resultar, ao menos, em problematizações e discussão de suas implicações.

Inegavelmente, não é fácil receber críticas a um trabalho que demandou horas de dedicação e esforço intelectual no seu desenvolvimento: a repulsa inicial às problematizações apontadas às nossas próprias teses é plenamente natural. ${ }^{6}$ Assim, após confirmar o recebimento ao editor e responder sobre a viabilidade do prazo assinalado, ${ }^{7}$ em regra,

5 ANNESLEY. Top 10 Tips for Responding to Reviewer and Editor Comments, p. 55; MUCHENJE. Editorial: How to respond to reviewers' comments, p. 116.

6 MAJUMDER. How do authors feel when they receive negative peer reviewer comments? p. 33-34.

7 O prazo indicado aos autores para retorno das correções considera a profundidade das revisões sugeridas e a situação do processo editorial da revista, para viabilizar a publicação do artigo em número posterior assim que possível. Se for inviável o cumprimento a tal prazo, provavelmente haverá possibilidade de prorrogação ou postergação para número subsequente. Assim, solicita-se que isso seja comunicado ao editor imediatamente, para se buscar a opção mais adequada. Vale ressaltar que uma demora excessiva 
sugere-se que o autor leia os pareceres e se afaste dessa tarefa por algum tempo, para digerir as críticas e possibilitar a dissipação da natural indignação que decorre da fragilização de suas ideias tão dedicadamente desenvolvidas durante a redação do artigo. ${ }^{8}$ Ou, nos termos de Thomas Annesley, "fique com raiva, mas supere isso". ${ }^{9}$ Certamente, uma posterior releitura das críticas permitirá uma análise muito mais racional, de modo a propiciar uma consideração melhor orientada sobre as possíveis contribuições apontadas.

Ao ler novamente os pareceres, esteja aberto a revisar suas premissas e buscar um efetivo aprimoramento ao artigo. Não se iluda, o editor consegue perceber facilmente a diferença entre quem realmente se dedicou a aprimorar o trabalho e quem tentou responder do modo mais rápido e raso as críticas para alterar o mínimo do texto original submetido.

Deverá ser encaminhada, no prazo estabelecido, a nova versão do artigo. Todas as alterações devem ser destacadas em cor distinta ou com marcações da opção de "controlar alterações" do Word ativada. ${ }^{10}$ Em regra, no e-mail de comunicação da decisão preliminar, o editor enviará em anexo o arquivo do artigo já com formatações e elementos complementares adotados na RBDPP. Tal arquivo estará bloqueado, de modo que todas as modificações ficarão automaticamente marcadas. Esse destaque aos aprimoramentos realizados é indispensável, pois não é obrigação do editor posteriormente dedicar horas comparando manualmente as versões do artigo. ${ }^{11}$

por inércia do autor pode acarretar a rejeição do artigo e a necessidade de reinício de todo o processo editorial.

8 SHAW. Responding to reviewers, p. 1261.

9 ANNESLEY. Top 10 Tips for Responding to Reviewer and Editor Comments, p. 551 (tradução livre).

10 KOTZ; CALS. Effective writing and publishing scientific papers, part XII: responding to reviewers, p. 243.

11 "Não é responsabilidade do revisor (ou editor) ser um detetive de manuscritos e gastar tediosas horas identificando alterações por comparação das versões revisada e original do artigo. Manuscritos sem a clara identificação das modificações devem ser retornados aos autores e postergados, até que uma revisão apropriada seja enviada" (ROSENFELD. How to review journal manuscripts, p. 484) (tradução livre). 
Além do envio do artigo com as correções marcadas, deve-se encaminhar documento com as respostas específicas aos pareceres. Como padrão, a equipe editorial da RBDPP anexará ao e-mail da decisão editorial um arquivo com as instruções e os pareceres, para facilitar a réplica do autor, mas, se isso não ocorrer, copie todos os pareceres da equipe editorial e dos avaliadores. Segundo Hywel Williams, as regras de ouro ao responder as críticas são: “1) responda de modo completo; 2) responda educadamente; 3 ) responda com argumentos consistentes". ${ }^{2}$

Como padrão, por se adotar na RBDPP uma orientação de proatividade na postura dos editores no manejo das submissões, ${ }^{13}$ juntamente às avaliações dos revisores anônimos, encaminha-se um parecer da equipe editorial, redigido pelo(a)(s) editor(es) responsável(is). Ali, o editor realizará a consolidação das avaliações dos revisores e incluirá também críticas e sugestões complementares, além de motivar a decisão editorial. Importante notar que a decisão final sobre a aprovação ou rejeição do artigo é da equipe editorial, que deve ser orientada pelos avaliadores, mas não necessariamente vinculada a eles. O autor deverá responder com especial atenção ao parecer da equipe editorial, mas isso não supre a necessidade de réplica específica a cada crítica dos revisores, separadamente. ${ }^{14}$

Então, responda item-por-item, ${ }^{15}$ abaixo de cada crítica/sugestão (que, preferencialmente, estarão numeradas), utilizando outra cor de texto para ressaltar e diferenciar. Assim, "a resposta ponto-por-ponto deve se dirigir às problemáticas diretamente, apresentando uma descrição das alterações realizadas ou uma explicação do porquê a sugestão

12 WILLIAMS. How to reply to referees' comments when submitting manuscripts for publication, p. 80 (tradução livre).

13 Sobre isso, ver: VASCONCELLOS. Editorial: a função do periódico científico e do editor para a produção do conhecimento no Direito e nas ciências criminais, p. 9-17. Conforme Bruno Frey, um modo de tentar reduzir as arbitrariedades e abusividades do processo editorial científico é a atuação proativa dos editores no sentido de controlar e consolidar os pareceres dos avaliadores anônimos (FREY. Publishing as prostitution? p. 207 e 218).

14 Sobre isso: SHAW. Responding to reviewers, p. 1261.

15 FERREIRA. Responder aos Revisores, p. 3; WILLIAMS. How to reply to referees' comments when submitting manuscripts for publication, p. 81; ROSENFELD. How to review journal manuscripts, p. 484. 
foi deixada de lado". ${ }^{16}$ Ou seja, indique de modo objetivo e consistentemente motivado o que foi atendido (e onde houve modificação no artigo para tanto) ou as razões da recusa, explicando por que a crítica ou sugestão é equivocada, impertinente ou inviável.

Portanto, é plenamente aceitável que o autor não atenda integralmente o parecer, mas isso precisa ser feito de modo respeitoso e com a apresentação de uma motivação razoável. ${ }^{17}$ Tenha sempre em mente que as críticas encaminhadas nem sempre são cabais e corretas, e o editor tem plena noção de que às vezes algumas problematizações são injustificadas ou sugestões são inviáveis. Por uma questão de transparência, em regra todos os pareceres são encaminhados ao autor com o conteúdo integral das críticas redigidas pelos avaliadores, pois alterações pelo editor somente se justificam em casos de abusividade ou imprecisão manifestas.

Ou seja, exatamente com a intenção de ajudar ao máximo o autor, o avaliador ou o editor acabam por indicar críticas não tão bem-acabadas ou até mesmo ideias que eles próprios não estão seguros, mais como um incentivo ao debate. Portanto, o editor não tenderá a adotar uma posição de invariável adoção das críticas opostas ao artigo. Se o autor responder respeitosamente, motivando adequadamente as recusas, provavelmente o editor não irá insistir e impor alterações em um ou outro sentido.

Sabe-se que avaliadores e editores podem estar errados. ${ }^{18}$ Contudo, isso não quer dizer que o autor possa simplesmente ignorar a crítica apontada: se alguém não compreendeu adequadamente o que se queria dizer, provavelmente haverá como aprimorar a redação do texto para torná-lo mais claro e preciso. ${ }^{19}$ Diante disso, não seja rude ao responder, simplesmente expondo o erro do avaliador, mas, além de fazer

16 SAMET. Dear Author - Advice from a Retiring Editor, p. 435 (tradução livre).

17 KOTZ; CALS. Effective writing and publishing scientific papers, part XII: responding to reviewers, p. 243; CUMMINGS; RIVARA. Responding to reviewer's comments on submitted articles, p. 106.

18 WILLIAMS. How to reply to referees' comments when submitting manuscripts for publication, p. 82.

19 ANNESLEY. Top 10 Tips for Responding to Reviewer and Editor Comments, p. 552 . 
isso de modo gentil, indique o que foi alterado no trabalho para evitar que outros leitores tenham novamente essa compreensão equivocada.

Entretanto, recusas injustificadas, respostas agressivas ou críticas ignoradas acarretarão a rejeição ou uma nova rodada de correções, em que o editor poderá questionar a motivação exposta e indicar questões não consideradas. Por exemplo, sugestões de bibliografia diretamente relacionadas ao tema do artigo e disponíveis com acesso viável (como em biblioteca online, por ex., do IBCCRIM) não são legitimamente recusadas somente por falta de interesse ou tempo do autor, considerando que um prazo razoável é normalmente concedido para sua leitura e inclusão.

O fundamental é que o autor demonstre interesse em efetivamente questionar suas premissas e suas teses, no sentido de se dispor a revisar, corrigir, ampliar, aprofundar e reescrever o texto tanto quanto for necessário para o seu fortalecimento como fonte confiável e consistente de conhecimento. ${ }^{20} \mathrm{Ou}$ seja, reitera-se: o autor não pode pensar que o desenvolvimento do artigo se encerra com a submissão ao periódico, mas ter a plena noção de que muito ainda poderá ser feito para seu aprimoramento no decorrer do processo editorial.

Sem dúvidas, as críticas expostas pelos pareceristas e pela equipe editorial não pretendem obrigar o autor a alterar seus posicionamentos, mas, bem pelo contrário, reforçá-los. ${ }^{21}$ As problematizações

20 “É um mito pensar que autores não podem discordar dos pareceres e ter um resultado positivo. O que é importante é que o autor justifique cuidadosamente a discordância. Primeiramente, avaliadores pretendem se assegurar que os autores consideraram com seriedade a questão e, fundamentalmente, tentaram buscar uma solução" (SHAW. Responding to reviewers, p. 1262) (tradução livre).

21 Uma forte crítica ao sistema de controle por pares para análise e seleção de trabalhos científicos é a possibilidade de abusos por avaliadores e editores, que, por meio das críticas e imposições abusivas de correções, desvirtuariam as ideias originais e impediriam teses inovadoras no campo do conhecimento. Sobre isso, ver: FREY. Publishing as prostitution? p. 205-223; CASADEVALL; FANG. Is peer review censorship? p. 1273-1274; BEDEIAN. Balancing authorial voice and editorial omniscience, p. 134-142. Diante disso, embora a RBDPP adote posição em prol do fortalecimento do controle por pares e das rodadas de correções, ressalta-se que os autores têm total liberdade para responder negativamente a eventuais críticas e sugestões abusivas ou inviáveis, motivando adequadamente tais recusas. Além disso, as problematizações e 
de conteúdo opostas às teses sustentadas no artigo almejam resultar em aprimoramento e fortalecimento do texto submetido, por exemplo, com o rebatimento de tais críticas no próprio corpo do artigo, além da motivação da resposta ao parecer na carta ao editor. Ou seja, tente não adotar uma posição defensiva para blindar seus pensamentos e somente atacar as críticas, mas se esforce para ficar aberto ao debate de modo a questionar e refletir sobre suas teses. ${ }^{22}$

Portanto, tão (ou mais) importante do que responder às críticas e aos questionamentos na carta-resposta do autor é que se revise e aprimore efetivamente o texto do artigo, incluindo tais argumentos para eventualmente reforçar suas teses. ${ }^{23}$ Assim, "você pode perceber que, ao explicar os motivos para manter parte do texto como está, algumas das frases e ideias utilizadas para responder ao avaliador poderiam ser úteis para adição no parágrafo em questão de modo a ajudar outros leitores a entender melhor o trabalho". ${ }^{24}$

Evite ao máximo pessoalizar as críticas apresentadas. ${ }^{25}$ Seguramente, os avaliadores e os editores devem ter tentado adotar um tom respeitoso e construtivo, ${ }^{26}$ mas algumas vezes é inevitável que o texto redigido possa ser interpretado de modo distinto do almejado ou a problematização se apresente muito rigorosa, ainda mais em razão da tendencial frieza do contato formal por e-mail. Tenha certeza que a in-

sugestões de complementação de bibliografia não pretendem obrigar o autor a alterar posicionamentos ou seguir determinada corrente, mas, ao contrário, almejam que o pesquisador considere visões distintas para verificar e aprimorar seus próprios argumentos.

22 "Como uma dica, se você perceber que discorda/recusa com muita frequência, isso pode ser um sinal de que está adotando uma postura defensiva e resistindo à necessidade de realizar mudanças consistentes" (SHAW. Responding to reviewers, p. 1262) (tradução livre). WINCK; WEDZICHA; FONSECA; AZEVEDO. To publish or perish, p. 98. ANNESLEY. Top 10 Tips for Responding to Reviewer and Editor Comments, p. 552 (tradução livre).

25 WILLIAMS. How to reply to referees' comments when submitting manuscripts for publication, p. 81.

26 “Como autor, é importante ter em mente que os comentários de avaliadores que aparentarem diretos e fortes são, na grande maioria, feitos com o objetivo de uma crítica construtiva" (SHAW. Responding to reviewers, p. 1261) (tradução livre). 
tenção foi positiva, no sentido de incentivar o aprimoramento do texto, pelo simples fato de que todos os envolvidos atuam voluntariamente, ou seja, dedicaram tempo e esforço intelectual na análise do seu artigo. ${ }^{27}$

Por fim, vale ressaltar que nem sempre as avaliações dos pareceristas são uniformes e, por isso, pode haver divergências entre as críticas e sugestões. Isso não afasta a necessidade de resposta do autor, de modo que não basta apontar tal contradição como um pretenso esvaziamento dos pareceres. ${ }^{28}$ Trata-se de um ponto positivo das diferentes premissas adotadas por cada revisor. Diante disso, o autor deve considerar ambas as problematizações e replicar de modo uniforme a elas.

\section{REFERÊNCIAS}

AGARWAL, Rajshree; ECHAMBADI, Raj; FRANCO, April M.; SARKAR, Mb. Reap rewards: maximizing benefits from reviewer comments. Academy of Management Journal, vol. 49, n. 2, p. 191-196, 2006. https://doi.org/10.5465/ amj.2006.20786044

ANNESLEY, Thomas M. Top 10 Tips for Responding to Reviewer and Editor Comments. Clinical Chemistry, vol. 57, n. 4, p. 551-554, 2011. https://doi. org/10.1373/clinchem.2011.162388

BEDEIAN, Arthur G. Balancing authorial voice and editorial omniscience: the "it's my paper and I'll say what I want to" versus "ghostwriters in the sky" minuet. In: BARUCH, Y.; KONRAD, A.; AGUINIS, H.; STARBUCK, W. (eds.). Opening the black box of editorship. New York: Palgrave Macmillan, 2008. p. 134142. https://doi.org/10.1057/9780230582590_14

CASADEVALL, Arturo; FANG, Ferric C. Is peer review censorship? Infection and immunity, v. 77, n. 4, p. 1273-1274, abr. 2009. https://doi.org/10.1128/ IAI.00018-09

CUMMINGS, Peter; RIVARA, Frederick P. Responding to reviewer's comments on submitted articles. Archives of Pediatrics and Adolescent Medicine, v. 156, n. 2 , p. 105-107, 2002. https://doi.org/10.1001/archpedi.156.2.105

27 AGARWAL; ECHAMBADI; FRANCO; SARKAR. Reap rewards: maximizing benefits from reviewer comments, p. 193.

28 FERREIRA. Responder aos Revisores, p. 4. 
FERREIRA, Manuel A. S. P. V. Responder aos Revisores. Revista Ibero-Americana de Estratégia, vol. 3, n. 1, p. 1-6, jan./mar. 2014. https://doi.org/10.5585/riae. v13i1.2099

FREY, Bruno S. Publishing as prostitution? Choosing between one's own ideas and academic success. Public Choice, v. 116, p. 205-223, 2003. https://doi. org/10.1023/A:1024208701874

KOTZ, Daniel; CALS, Jochen W. L. Effective writing and publishing scientific papers, part XII: responding to reviewers. Journal of Clinical Epidemiology, vol. 67, n. 3, p. 243, 2014. https://doi.org/10.1016/j.jclinepi.2013.10.003

MAJUMDER, Kakoli. How do authors feel when they receive negative peer reviewer comments? An experience from Chinese biomedical researchers. European Science Editing, vol. 42, n. 2, p. 31-35, mai. 2016.

MUCHENJE, Voster. Editorial: How to respond to reviewers' comments. South African Journal of Animal Science, vol. 47, n. 2, p. 116-117, 2017. https://doi. org/10.4314/sajas.v47i2.1

ROSENFELD, Richard. How to review journal manuscripts. OtolaryngologyHead and Neck Surgery, vol. 142, p. 472-486, 2010. https://doi.org/10.1016/j. otohns.2010.02.010

SAMET, Jonathan M. Dear Author - Advice from a Retiring Editor. American Journal of Epidemiology, vol. 150, n. 5, p. 433-436, 1999. https://doi.org/10.1093/ oxfordjournals.aje.a010030

SHAW, Jason D. Responding to reviewers. Academy of Management Journal, v. 55, n. 6, p. 1261-1263, 2012. https://doi.org/10.5465/amj.2012.4006

SILVER, Pamela. Advice for early-career peer reviewers and authors responding to peer reviews. Freshwater Science, v. 35, n. 4, p. 1073-1075, 2016. https://doi. org/10.1086/688968

VASCONCELLOS, Vinicius G. Editorial: a função do periódico científico e do editor para a produção do conhecimento no Direito e nas ciências criminais. Revista Brasileira de Direito Processual Penal, Porto Alegre, vol. 3, n. 1, p. 9-17, jan./abr. 2017. https://doi.org/10.22197/rbdpp.v3i1.34

VASCONCELLOS, Vinicius G. Editorial: controle por pares e a função do revisor - premissas e orientações para uma avaliação consistente. Revista Brasileira de Direito Processual Penal, Porto alegre, vol. 3, n. 2, p. 437-458, mai./ago. 2017. https://doi.org/10.22197/rbdpp.v3i2.70

WILLIAMS, Hywel C. How to reply to referees' comments when submitting manuscripts for publication. Journal of the American Academy of Dermatology, $\mathrm{v}$. 51, n. 1, p. 79-83, jul. 2004. https://doi.org/10.1016/j.jaad.2004.01.049 
WINCK, J.C.; WEDZICHA, J.A.; FONSECA, J.A.; AZEVEDO, L.F. To publish or perish: how to review a manuscript. Revista Portuguesa de Pneumología, vol. 17, n. 2, p. 96-103, 2011. https://doi.org/10.1016/s2173-5115(11)70022-7

\section{Informações adicionais e declarações do autor (integridade científica)}

Agradecimentos (acknowledgement): Agradeço ao editor e amigo Caíque Galícia pela leitura crítica que contribuiu ao aprimoramento deste editorial.

Declaração de conflito de interesses (conflict of interest declaration): o autor confirma que não há conflitos de interesse na realização das pesquisas expostas e na redação deste editorial.

Declaração de autoria (declaration of authorship): todas e somente as pessoas que atendem os requisitos de autoria deste editorial estão listadas como autores.

Declaração de ineditismo e originalidade (declaration of originality): o autor assegura que o texto aqui publicado não foi divulgado anteriormente em outro meio e que futura republicação somente se realizará com a indicação expressa da referência desta publicação original; também atesta que não há plágio de terceiros ou autoplágio.

\section{COMO CITAR ESTE EDITORIAL:}

VASCONCELLOS, Vinicius G. Editorial: As rodadas de correções e a carta-resposta do autor à aprovação condicionada - sobre o controle e o aprimoramento dos artigos no processo editorial científico. Revista Brasileira de Direito Processual Penal, Porto Alegre, vol. 3, n. 3, p. 757-768, set./dez. 2017. https://doi.org/10.22197/rbdpp.v3i3.101

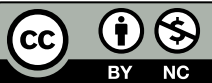

Esta obra está licenciada com uma Licença Creative Commons Atribuição-NãoComercial 4.0 Internacional. 